\title{
Application of Linguistic/Non-numeric Fuzzy Aggregation to the Ranking of Processed Crops
}

\author{
David Koloseni \\ Department of Mathematics, University of Dar es Salaam, Tanzania \\ E-mail:dkdavykol@gmail.com; koloseni.david@udsm.ac.tz
}

Received 22 Sep 2020, Revised 7 May 2021, Accepted 19 May 2021, Published May 2021

DOI: https://dx.doi.org/10.4314/tjs.v47i2.26

\begin{abstract}
A non-numeric fuzzy aggregation approach is applied for the fusion of information obtained from farmers and experts for evaluation and selection of alternatives under multiple criteria. The technique has the ability to assign linguistic variable to fused information and find consensus of gathered opinions from a number of experts on crop processing for each processed crop. The technique is illustrated with a crop processing problem by adding value to the crop and increase income to entrepreneurs. The proposed technique has been successfully applied to the ranking of the processed crops based on the expert's opinions, thus obtaining best preferences based on product, technology, marketing, and customer satisfaction. Five crops, namely beans, maize, rosella, sunflower and rice were ranked. Out of the five ranked crops, two processed crops (maize and sunflower) obtained high ranking.
\end{abstract}

Keywords: Linguistic variables, Fuzzy aggregation, Processed crops, Decision making.

\section{Introduction}

In many situations, various decisions have to be made, but before a decision is made, decision makers are supposed to collect, analyse and assess the information for processing in qualitative or quantitative forms or both. For example, in evaluating processed crops, phrases like very good product or very high technology used are very common in qualitative form instead of using numeric values (Levrat et al. 1997, Bordogna et al. 1997, Xu et al. 2012). Here the terms very good and very high are used to express the quality forms of the processed crops.

Crop processing focuses on resources optimization that leads to more profit to the farmer by lifting standards of living, and enhancing quality of life (Duque-Acevedo et al. 2020). However, crop processing can be affected by the fragmented nature of the market system, high transaction costs, lack of better facility storage to further commercialize the crops (Pingali et al. 2019).

Crop processing is an important step in stability and sustainability of economic development of any country. Crop processing adds value to the crops and when sold to the market the farmer gets more profit. However, it is not only the farmer who is benefiting but also the country receives tax. Processing reduces food losses and stabilizes seasonal fluctuations in the supply of food (Simonyan 2014).

In addition, processing of crops offers opportunities in terms of employment, reduces wastes due to spoilage and encourages development of technical skills.

Multi-criteria decision-making methods are usually applied to assess the best possible solution of a certain problem due to the complexity of things and uncertainty environment that results into ranking various 
choices of the alternatives (Cid-López et al. 2017). The materials selection method with 2 tuple linguistic variables is a compensatory multi-criteria method, in which, the changes in one criterion can be compensated for different variations in any other criteria. The method selects the alternative that represents the highest score, and compares the material candidates considering the established targets for each criterion with weights assigned by the decision makers involved in the materials selection process (Setti et al. 2019).

Balezentiene et al. (2013) proposed a multicriteria decision-making framework for prioritization of energy crops based on fuzzy MULTIMOORA method. The method enables to tackle imprecise information in which the set of alternatives were constructed from energy crops suitable for the Lithuanian climate. The fuzzy MULTIMOORA method was employed for data merging and ranking. Prabakaran et al. (2018) investigated the process of reducing the fertilizer consumption and improving the crop productivity using fuzzy decision support system, and the findings showed that, horticulture crops enjoy higher productivity ranging in over the two agro climate zones.

Other multi-criteria decision making (MCDM) that use linguistic variables to make decision include; fault identification in wide plants (Sánchez-Fernández et al. 2018), performance evaluation of sugar plants using a fuzzy technique for order preference by similarity to ideal solution (TOPSIS) method (Arslan and Çunkaş 2012). Raut et al. (2018) identified the crucial causal factors of postharvest losses in the fruits and vegetables supply chain in the Indian context and applied analytic hierarchy process (AHP) to ascertain the relative importance of these factors on a comparative basis. The developed model stressed the most critical factors that should be ranked for progressive post-harvest losses reduction, assessment of land suitability and agricultural production sustainability (FuzzyAHP-GIS) (Amini et al. 2020) to mention but a few.
The ranking of alternatives with respect to competitive criteria involves choosing feasible alternatives with conflicting criteria according to the linguistic performance values provided (Yang et al. 2017). Human beings have inherent preferences, which are vague and fuzzy. The vagueness and fuzziness can be well captured when applying linguistic variables to aggregate decision makers' opinions in making valuable decisions. Linguistic variables are more expressive and suitable to model real life situation than numerical values (Zadeh 1975). The non-numeric evaluated decision makers' opinions can be combined to reach a final decision.

Shakeel et al. (2020) developed aggregation operator based on Pythagorean uncertain linguistic hesitant fuzzy weight averaging operator. The operator was applied on financial decision making on the selection of financial services. Hotel selection method was developed based on simplified neutrosophic linguistic information with cloud model (Wang et al. 2018). Aggarwal (2016) proposed linguistic discriminative aggregation in MCDM that consider of both aprio weight information as well as variability in the evaluation of criterion.

Much has not been done in applying MCDM linguistics method on crop processing. This work applied linguistic fuzzy aggregation and ranking to the processed crops.

This study intended to rank the chosen five best performing processed crops which are beans, maize, sunflower, rosella and rice. These five crops were selected based on the opinion from small scale farmers. The ranking of crops helps famers to recognize which processed crops perform better in the markets and once cultivated and processed may attract more income and hence improve their economy. In addition, policy makers can use ranking of crops to monitor the performance of a particular crop as well as for benchmarking. 


\section{Materials and Methods Problem formulation}

The problem formulation presented in this paper has the following major components: the first component is a collection of processed crops that are mostly preferred by the farmers \{Beans, Maize, Sunflower, Rosella, Rice\}. These crops would be ranked after information fusion. The second component is a group of three agricultural extension officers (experts) $D M=\left\{D_{1}, D_{2}, D_{3}\right\}$. Their task is to comment on each sub-criterion, the comments will help decision makers to arrive at the feasible conclusion. The third component of the problem formulation consists of the set of criteria and their corresponding sub criteria that will be used in evaluating the suitability of all the processed crops. Finally, the fourth component consists of all processes of information aggregate of the expert comments to allow decision makers to make sound decisions.

In collecting information, each expert was given a form with a set of questions. The form consisted of questions relating to crops that are preferred for processing. The questions constituted to the criteria for each alternative.

Linguistic fuzzy aggregation technique

Table1: Descriptions of the sub-criteria

\begin{tabular}{|c|c|c|}
\hline Criteria & Sub-criteria & Descriptions \\
\hline \multirow[t]{4}{*}{ Product } & Branding & $\begin{array}{l}\text { A symbol, sign or logo that helps to identify or distinguish } \\
\text { one product from the other. }\end{array}$ \\
\hline & & Increases credibility and visibility of the product. \\
\hline & Delivery & $\begin{array}{l}\text { Time and ease to transfer product from sales/production } \\
\text { center to the customer. }\end{array}$ \\
\hline & Patent protection & Protection of exclusive right for the inversion of a product. \\
\hline Technology & $\begin{array}{l}\text { Payment } \\
\text { acquisition } \\
\text { Uniqueness }\end{array}$ & $\begin{array}{l}\text { Hiring or purchasing of external knowledge/innovation. } \\
\text { Ability to produce a product using technology the others do } \\
\text { not have. }\end{array}$ \\
\hline \multirow[t]{2}{*}{ Marketing } & Target & A group of customers, buyers and users of the product. \\
\hline & Competition & $\begin{array}{l}\text { Ability to produce a product that will contest among the } \\
\text { selling of the similar product that targets similar market or } \\
\text { customers so as to get more revenues. }\end{array}$ \\
\hline \multirow[t]{2}{*}{ Customer } & Willingness to pay & Purchasing power of a customer to pay. \\
\hline & Demand & $\begin{array}{l}\text { Desire and ability of a customer to purchase a product at a } \\
\text { given price. }\end{array}$ \\
\hline
\end{tabular}

This paper presents an approach that is applied to screening problems as suggested by Yager (1991). This approach allows preference information be expressed in by elements drawn Linear ordering allows experts to provide information about satisfaction in form of linguistic values such as high, medium, low. The fuzzy screening system has two steps:

1. Experts are asked to provide an evaluation of the alternatives. Evaluation process involves rating of each alternative on each of the criteria.

2. Aggregate individual expert evaluations to obtain an overall linguistic value for each object.

In this paper, three experts were asked to evaluate each alternative \{Beans, Maize, Sunflower, Rosella and Rice $\}$ on how well that alternative satisfies each of the criteria \{Product ( $C 1)$, Technology (C2), Marketing (C3) and Customer (C4)\}. The description of each criterion and the corresponding subcriteria are presented in Table 1 while Table 2 consists of linguistic variables and their corresponding scales. Evaluations for each alternative and satisfactions to criteria are given in Table 3. from a scale that requires linear ordering. 
Table 2: Linguistic variables and their respective scales

\begin{tabular}{lc}
\hline Linguistic variable & Scale \\
\hline Very high (VH) & $S_{5}$ \\
High (H) & $S_{4}$ \\
Medium (M) & $S_{3}$ \\
Low (L) & $S_{2}$ \\
Very low (VL) & $S_{1}$ \\
\hline
\end{tabular}

Table 3: Evaluation of each alternative for each criterion

\begin{tabular}{|c|c|c|c|c|c|}
\hline \multirow[b]{2}{*}{ Alternatives } & \multirow[b]{2}{*}{$\mathrm{DM}$} & \multicolumn{4}{|c|}{ Criteria } \\
\hline & & $\begin{array}{c}\text { Prod } \\
\text { C1 }\end{array}$ & $\begin{array}{c}\text { Tech } \\
\text { C2 }\end{array}$ & $\begin{array}{c}\text { Mark } \\
\text { C3 }\end{array}$ & $\begin{array}{c}\text { Cust } \\
\text { C4 }\end{array}$ \\
\hline \multirow{3}{*}{ Beans $A_{1}$} & D1 & $\mathrm{L}$ & $\mathrm{L}$ & $\mathrm{L}$ & $\mathrm{L}$ \\
\hline & D2 & $\mathrm{H}$ & $\mathrm{H}$ & VH & VH \\
\hline & D3 & VL & M & $\mathrm{H}$ & $\mathrm{H}$ \\
\hline \multirow[t]{3}{*}{ Maize $A_{2}$} & D1 & $\mathrm{VH}$ & VH & $\mathrm{H}$ & $\mathrm{H}$ \\
\hline & D2 & $\mathrm{H}$ & $\mathrm{H}$ & VH & VH \\
\hline & D3 & $\mathrm{L}$ & $\mathrm{H}$ & $\mathrm{L}$ & $\mathrm{L}$ \\
\hline Sunflower & D1 & $\mathrm{VH}$ & $\mathrm{H}$ & VH & $\mathrm{H}$ \\
\hline \multirow[t]{2}{*}{$A_{3}$} & D2 & $\mathrm{H}$ & VH & VH & $\mathrm{VH}$ \\
\hline & D3 & M & $\mathrm{H}$ & VH & $\mathrm{H}$ \\
\hline \multirow{3}{*}{ Rosella $A_{4}$} & D1 & $\mathrm{L}$ & $\mathrm{L}$ & $\mathrm{L}$ & $\mathrm{L}$ \\
\hline & D2 & $\mathrm{H}$ & $\mathrm{H}$ & $\mathrm{H}$ & $\mathrm{H}$ \\
\hline & D3 & $\mathrm{L}$ & $\mathrm{H}$ & VL & $\mathrm{H}$ \\
\hline \multirow[t]{3}{*}{ Rice $A_{5}$} & D1 & $\mathrm{L}$ & $\mathrm{L}$ & $\mathrm{L}$ & $\mathrm{L}$ \\
\hline & D2 & $\mathrm{H}$ & $\mathrm{H}$ & $\mathrm{H}$ & $\mathrm{H}$ \\
\hline & D3 & $\mathrm{M}$ & $\mathrm{H}$ & $\mathrm{H}$ & $\mathrm{H}$ \\
\hline
\end{tabular}

Next, the experts' evaluations are combined to obtain an overall evaluation for each alternative based upon the ordered weighting averaging (OWA) operator.

The first step is for the decision marker to provide an aggregation function denoted by $\mathrm{Q}$. For each particular number $i, 1 \leq i \leq n$ the function $Q(i)=S_{b(i)}$ indicates how the decision maker is satisfied in passing an alternative. The values for the function $Q(i)$ should be drawn from the scale $S$ described in Table 1. In defining the function $Q(i)$, Yager (1991) introduced an operation Int $[a]$ as returning the integer value that is closest to the number $a$. Let $q=5$ be the number of points in the scale (the cardinality of S) and $r=3$ be the number of experts (decision markers) participating. The function which enumerates the average $Q_{A}$ for all $k=0,1,2, \ldots, r$ is denoted as

$$
\begin{gathered}
Q_{A}(k)=S_{b(k)}, \text { where } \\
b(k)=\operatorname{Int}\left[1+k \cdot \frac{q-1}{r}\right], k=0,1,2, \ldots, r
\end{gathered}
$$

Here the average aggregation function $Q_{A}$ is applied with $r=3$ and $q=5$ to obtain

$$
Q_{A}(1)=S_{1}, Q_{A}(2)=S_{4}, Q_{A}(3)=S_{5} \text {. }
$$

Having obtained proper aggregation function, $Q_{A}$, then the OWA method is used to aggregate decision maker opinions on each of the criteria. The first step in the OWA method is to order the criteria scores in descending order in which $B_{i}$ is denoted as the $i^{t h}$ highest score among the expert unit scores for the alternative (crop).

To find the overall evaluation for the $j^{\text {th }}$ alternative denoted by $A_{j}$, we calculate, $A_{j}=\max _{i}\left\{Q_{A}(i) \wedge B_{i}\right\}$, where $i=1,2, \ldots, r$

From the equation, $A_{j}=\max _{i}\left\{Q_{A}(i) \wedge B_{i}\right\}, B_{i}$ is seen as the worst of the $j^{\text {th }}$ top scores while $Q_{A}(i)$ expresses an indication of how important the decision maker feels the support of at least $j^{\text {th }}$ expert is. The term $\left\{Q_{A}(i) \wedge B_{j}\right\}$ fives the weighting of an alternative $j$ best score. In addition, it satisfies decision making requirement that a number of $j$ experts support the criteria.

For example, in the case of alternative (Beans) $A_{1}$ to find overall evaluations from the three decision makers for the criteria product we have,

$$
\begin{gathered}
A_{1}=\max _{i=1}\left\{Q_{A}(1) \wedge B_{1}, Q_{A}(2) \wedge B_{2}, Q_{A}(3)\right. \\
\left.\wedge B_{3}\right\} \\
A_{1}=\max _{i=1}\{(V L \wedge V H),(H \wedge L),(V H \wedge V L)\} \\
A_{1}=\max _{i=1}\{V L, L, V L\}=L
\end{gathered}
$$

For technology criteria,

$$
\begin{gathered}
A_{1}=\max _{i=1}\{(V L \wedge H),(H \wedge M),(V H \wedge L)\} \\
A_{1}=\max _{i=1}\{V L, M, L\}=M
\end{gathered}
$$

For marketing criteria,

$$
\begin{gathered}
A_{1}=\max _{i=1}\{(V L \wedge V H),(H \wedge H),(V H \wedge L)\} \\
A_{1}=\max _{i=1}\{V L, H, L\}=H
\end{gathered}
$$


For customer criteria,

$$
\begin{gathered}
A_{1}=\max _{i=1}\{(V L \wedge V H),(H \wedge H),(V H \wedge L)\} \\
A_{1}=\max _{i=1}\{V L, H, L\}=H
\end{gathered}
$$

Similarly, the same technique is used to find overall evaluations from the three decision makers for the all criteria to each remaining alternative (Maize, Sunflower, Rosella and Rice). The overall evaluations results are presented in Table 4.

Table 4: Overall aggregations for each alternative and its corresponding criteria

\begin{tabular}{lcccc}
\hline \multirow{2}{*}{ Alternative } & \multicolumn{4}{c}{ Criteria } \\
\cline { 2 - 5 } & Prod & Tech & Mark & Cust \\
& $\mathrm{C} 1$ & $\mathrm{C} 2$ & $\mathrm{C} 3$ & $\mathrm{C} 4$ \\
\hline Beans $A_{1}$ & $\mathrm{~L}$ & $\mathrm{M}$ & $\mathrm{H}$ & $\mathrm{H}$ \\
Maize $A_{2}$ & $\mathrm{VH}$ & $\mathrm{H}$ & $\mathrm{H}$ & $\mathrm{H}$ \\
Sunflower & $\mathrm{H}$ & $\mathrm{H}$ & $\mathrm{VH}$ & $\mathrm{H}$ \\
$A_{3}$ & & & & \\
Rosella $A_{4}$ & $\mathrm{~L}$ & $\mathrm{H}$ & $\mathrm{L}$ & $\mathrm{H}$ \\
Rice $A_{5}$ & $\mathrm{M}$ & $\mathrm{H}$ & $\mathrm{H}$ & $\mathrm{H}$ \\
\hline
\end{tabular}

Prod $=$ Product, Tech $=$ Technology,

Mark $=$ Marketing, Cust $=$ Customer

Table 5 consists of main criteria with importance weights for each sub-criteria provided by the three decision makers.

\begin{tabular}{|c|c|c|c|c|}
\hline \multirow[t]{2}{*}{$\begin{array}{l}\text { Main } \\
\text { Criteria }\end{array}$} & \multirow[t]{2}{*}{ Sub-Criteria } & \multicolumn{3}{|c|}{$\begin{array}{l}\text { Importance } \\
\text { weights }\end{array}$} \\
\hline & & D1 & $\mathrm{D} 2$ & D3 \\
\hline \multirow[t]{3}{*}{ Product } & Branding & VH & $\mathrm{H}$ & $\mathrm{VH}$ \\
\hline & Delivery & $\mathrm{H}$ & VH & VH \\
\hline & $\begin{array}{l}\text { Patent } \\
\text { protection }\end{array}$ & VH & $\mathrm{H}$ & $\mathrm{H}$ \\
\hline \multirow[t]{2}{*}{ Technology } & $\begin{array}{l}\text { Payment \& } \\
\text { acquisition }\end{array}$ & $\mathrm{H}$ & VH & $\mathrm{H}$ \\
\hline & Uniqueness & VH & $\mathrm{H}$ & $\mathrm{H}$ \\
\hline \multirow[t]{2}{*}{ Marketing } & Target & VH & VH & $\mathrm{H}$ \\
\hline & Competition & VH & VH & $\mathrm{H}$ \\
\hline \multirow[t]{3}{*}{ Customer } & $\begin{array}{l}\text { Willingness } \\
\text { to pay }\end{array}$ & M & M & $\mathrm{H}$ \\
\hline & Heterogeneity & M & M & $\mathrm{H}$ \\
\hline & Demand & $\mathrm{H}$ & M & M \\
\hline
\end{tabular}

Table 5: Main criteria with importance weights
Using fuzzy relation called max-min composition; these sub-criteria importance weights can be aggregated.

For the main criteria Product, the sub-criteria importance weights are aggregated as follows:

$$
\begin{gathered}
\text { Product }=\max _{C 1}\left\{\min _{1}\left(D_{1 B}, D_{1 D}, D_{1 P}\right), \min _{2}\left(D_{2 B}, D_{2 D}, D_{2 P}\right),\right. \\
\left.=\max _{C 1}\left\{\min _{D 1}(V H \wedge V H \wedge H), D_{D 2}, D_{3 P}\right)\right\} \\
\left.\wedge H), \min _{D 3}(V H \wedge V H \wedge H)\right\} \\
\text { Product }=\max (H, H, H)=H
\end{gathered}
$$

where $\left(D_{1 B}, D_{1 D}, D_{1 P}\right)$ represents importance weight on branding, delivery and patent protection sub-criteria by the first, second and

\begin{tabular}{|c|c|c|c|c|}
\hline Main criteria & Prod & Tech & Mark & Cust \\
\hline Importance weight & $\mathrm{H}$ & $\mathrm{H}$ & $\mathrm{H}$ & $\mathrm{M}$ \\
\hline
\end{tabular}
third decision makers, respectively. The same technique is applied to the remaining criteria such as technology, marketing and customer. The results are presented in Table 6 .

Table 6: Aggregate importance weights for each main criterion

The final fusion of all information is obtained by combining the information recorded in Table 3 and Table 5. The aggregation involves consolidated importance weight for each criteria and experts' evaluations on each criterion.

To obtain the overall evaluation to each processed crop as given by the experts, we take the negation of the importance weight of each criterion. The negation of the scale used is the one suggested by Yager (1991),

$$
\operatorname{Neg}\left(S_{i}\right)=S_{q-i+1}, \text { where } q=\mathbf{5}
$$

The negation process for the importance provides the following results in Table 7.

Table 7: Negation process results

\begin{tabular}{cccccc}
\hline$S_{i}$ & $S_{1}$ & $S_{2}$ & $S_{3}$ & $S_{4}$ & $S_{5}$ \\
\hline $\operatorname{Neg}\left(S_{i}\right)$ & $S_{5}$ & $S_{4}$ & $S_{3}$ & $S_{2}$ & $S_{1}$ \\
\hline
\end{tabular}


To find the overall unit evaluation score for each processed crop by each expert, denoted by $\boldsymbol{U}$, the following relation is used in the calculation:

$$
U=\min _{j}\left\{\max \left\{\operatorname{Neg}\left(I_{j}\right), P_{j}\right\}\right\}
$$

Where $\boldsymbol{I}_{\boldsymbol{j}}$ denotes the importance of the $\boldsymbol{j}^{\boldsymbol{t h}}$ criterion and $\boldsymbol{P}_{\boldsymbol{j}}$. is rating of the alternative on the $\boldsymbol{j}^{\text {th }}$ criterion by the expert.

For example, score for the beans and their respective importance weights for each criterion are as shown in Table 8.

Table 8: The scores and their importance

\begin{tabular}{lllll}
\hline Criteria & $\mathrm{C} 1$ & $\mathrm{C} 2$ & $\mathrm{C} 3$ & $\mathrm{C} 4$ \\
\hline Beans $\left(\boldsymbol{P}_{\boldsymbol{j}}\right)$ & $L$ & $M$ & $H$ & $H$ \\
Importance $\boldsymbol{I}_{\boldsymbol{j}}$ & $H$ & $H$ & $H$ & $M$ \\
\hline
\end{tabular}

Unit score for beans

$\boldsymbol{U}$

$=\min _{j}\{\max \{\operatorname{Neg}(H), L\}, \max \{N \operatorname{eg}(H), M\}$,

$\max \{\operatorname{Neg}(H), H\}, \max \{\operatorname{Neg}(M), H\}\}\}$

$U=\min _{j}\{\max \{L, L\}, \max \{L, M\}$,

$$
\begin{gathered}
\max \{\{L, H\}, \max \{M, H\}\}\} \\
U=\min _{j}\{L, M, H, H\}=L
\end{gathered}
$$

So, the overall score for beans is Low (L). The low performance for Beans is contributed by the fact that its aggregate score on the main criterion (product) is low which has high importance.

For the maize crop,

$\boldsymbol{U}$

$=\min _{j}\{\max \{\operatorname{Neg}(H), V H\}, \max \{\operatorname{Neg}(H), H\}$, $\max \{\operatorname{Neg}(H), H)\}, \max \{N \operatorname{eg}(M), H\}\}$

$$
\begin{gathered}
U=\min _{j}\{\max \{L, V H\}, \max \{L, H\}, \\
\max \{\{L, H\}, \max \{M, H\}\}\} \\
U=\min _{j}\{V H, H, H, H\}=H
\end{gathered}
$$

So the overall score for Maize is High $(\mathrm{H})$. For Sunflower,

$$
\begin{gathered}
U \\
=\min _{j}\{\max \{\operatorname{Neg}(H), H\}, \max \{\operatorname{Neg}(H), H\}, \\
\max \{\operatorname{Neg}(H), V H\}, \max \{\operatorname{Neg}(M), H\}\} \\
U=\min _{j}\{\max \{L, H\}, \max \{L, H\}, \\
\quad \max \{\{L, V H\}, \max \{M, H\}\}\} \\
U=\min _{j}\{H, H, V H, H\}=H
\end{gathered}
$$

So the overall score for Sunflower is High $(\mathrm{H})$.

For Rosella,

$\boldsymbol{U}$

$\left.=\min _{j}\{\max \{\operatorname{Neg}(H), L)\}, \max \{\operatorname{Neg}(H), H)\right\}$,

$$
\max \{\operatorname{Neg}(H), L)\}, \max \{N \operatorname{eg}(M), H\}\}
$$$$
U=\min _{j}\{\max \{L, L\}, \max \{L, H\},
$$$$
\max \{\{L, L\}, \max \{M, H\}\}\}
$$

$$
\boldsymbol{U}=\min _{j}\{L, H, L, H\}=L
$$

So the overall score for Rosella is Low (L).

For rice,

$\boldsymbol{U}$

$$
\begin{gathered}
=\min _{j}\{\max \{N \operatorname{eg}(H), M\}, \max \{N \operatorname{eg}(H), H\}, \\
\max \{N \operatorname{eg}(H), H\}, \max \{N \operatorname{eg}(M), H\}\} \\
U=\min _{j}\{\max \{L, M\}, \max \{L, H\}, \\
\max \{\{L, H\}, \max \{M, H\}\}\} \\
U=\min _{j}\{M, H, H, H\}=M
\end{gathered}
$$

So the overall score for rice is Medium (M).

\section{Results and Discussion}

Experts' evaluations for each alternative (processed crop) and satisfaction to each criterion were combined to obtain non-numeric (linguistic) overall evaluation for each alternative based upon OWA operator. The overall linguistic scores for each processed crop are shown in Table 9.

Table 9: Linguistic scores

\begin{tabular}{ll}
\hline Processed crop & Overall linguistic score \\
\hline Beans & Low $(\mathrm{L})$ \\
Maize & $\operatorname{High}(\mathrm{H})$ \\
Sunflower & $\operatorname{High}(\mathrm{H})$ \\
Rosella & Low $(\mathrm{L})$ \\
Rice & Medium (M) \\
\hline
\end{tabular}


The preference of the five selected processed crops showed that the most preferred crops are maize and sunflower while the performance of rice is medium and for the beans and rosella crops they are lowly preferred. Hence, ranking of the processed crops can be represented as follows:

Maize $=$ Sunflower $>$ Rice $>$ Beans $=$ Rosella

The obtained ranking of the processed crops revealed that Maize and Sunflower crops perform well in the market and customers are willing to pay for the products. Therefore, farmers or entrepreneurs can improve their livelihood status by engaging in the production and processing of such crops.

\section{Conclusion}

A technique to be used in the ranking of processed crops is applied without resorting to numerical values. Using this technique, a decision maker can advise policy makers to put in place a policy that allows the government to emphasize on which crops that can be processed and do well in the markets due to their conflicting criteria and preference to consumers. Finally, this work has provided the whole procedure and presented an example to illustrate it.

\section{References}

Aggarwal M 2016 Linguistic discriminative aggregation in multicriteria decision making. Int. J. Intell. Syst. 31(6): 529-555.

Amini S, Rohani A, Aghkhani MH, Abbaspour-Fard $\mathrm{MH}$ and Asgharipour MR 2020 Assessment of land suitability and agricultural production sustainability using a combined approach (Fuzzy-AHP-GIS): A case study of Mazandaran province-Iran Inf. Process. Agric. 7(3): 384-402.

Arslan M and Çunkaş M 2012 Performance evaluation of sugar plants by fuzzy technique for order performance by similarity to ideal solution (TOPSIS). Cybern. Syst. 43(7): 529-548.

Balezentiene L, Streimikiene D and Balezentis T 2013 Fuzzy decision support methodology for sustainable energy crop selection. Renew. Sustain. Energy Rev. 17: 83-93.

Bordogna G, Fedrizzi M and Pasi G 1997 A linguistic modeling of consensus in group decision making based on OWA operators IEEE Transactions on Systems, Man, and Cybernetics-Part A: Systems and Human 27: 126-133.

Cid-López A, Hornos MJ, Carrasco RA, Herrera-Viedma E and Chiclana F 2017 Linguistic multi-criteria decision-making model with output variable expressive richness. Expert Syst. Appl. 83: 350-362.

Duque-Acevedo M, Belmonte-Ureña LJ, Cortés-García FJ and Camacho-Ferre, F 2020 Agricultural waste: review of the evolution, approaches and perspectives on alternative uses. Global Ecology and Conservation 22: e00902.

Gardas BB, Raut RD, and Narkhede B 2018 Evaluating critical causal factors for postharvest losses (PHL) in the fruit and vegetables supply chain in India using the DEMATEL approach. J. Clean. Prod. 199: 47-61.

Levrat L, Voisin A, Bombardier S and Brémont J 1997 Subjective evaluation of car seat comfort with fuzzy set techniques, Int. J. Intell. Syst. 12: 891-913.

Pingali P, Aiyar A, Abraham M and Rahman A 2019 Linking farms to markets: reducing transaction costs and enhancing bargaining power. Transforming food systems for a rising India (pp. 193-214), Springer.

Prabakaran G, Vaithiyanathan D and Ganesan M 2018 Fuzzy decision support system for improving the crop productivity and efficient use of fertilizers. Comput. Electron. Agric. 150: 88-97.

Raut RD, Gardas BB, Kharat M and Narkhede B 2018 Modeling the drivers of postharvest losses-MCDM approach. Comput. Electron. Agric. 154: 426-433.

Sánchez-Fernández A, Sainz-Palmero GI, Benítez JM and Fuente MJ 2018 Linguistic OWA and two time-windows based fault identification in wide plants. Comput. Chem. Engin. 115: 412-430. 
Setti D, Verona MN, Medeiros BB and Restelli A 2019 Materials selection using a 2-tuple linguistic multi-criteria method. Mater. Res. 22.

Shakeel M, Shahzad M and Abdullah S 2020 Pythagorean uncertain linguistic hesitant fuzzy weighted averaging operator and its application in financial group decision making. Soft Comput. 24: 1585-1597.

Simonyan KJ 2014 Cassava post-harvest processing and storage in Nigeria: a review. Afr. J. Agric. Res. 9(53): 3853-3863.

Wang JQ, Tian CQ, Zhang X, Zhang HY and Wang TL 2018 Multi-criteria decisionmaking method based on simplified neutrosophic linguistic information with cloud model. Symmetry 10(6): 197.

Xu Y, Merigó JM and Wang H 2012 Linguistic power aggregation operators and their application to multiple attribute group decision making Appl. Math. Model. 36(11): 5427-5444.

Yager RR 1991 A non-numeric approach to multi-criteria/multi-expert aggregation based on approximate reasoning. In Uncertainty Proceedings Morgan Kaufmann 433-437.

Yang WE, Ma CQ and Han ZQ 2017 Linguistic multi-criteria decision-making with representing semantics by programming Int. J. Syst. Sci. 48(2): 225235.

Zadeh LA 1975 The concept of a linguistic variable and its application to approximate reasoning-I. Inf. Sci. 8(3): 199-249. 